\title{
I Doping $1 \mathrm{D} \mathrm{Li}_{4} \mathrm{Ti}_{5} \mathrm{O}_{12}$ Nanofibers as Anode Materials for Lithium-Ion Battery
}

\author{
Kai Yang ${ }^{1}$, Zhanyu $\mathrm{Li}^{2}$, Yuguang Zhao ${ }^{2}$, Yudong Wang $^{2}$, Fei Gao ${ }^{1}$, Jianling $\mathrm{Li}^{2, *}$ \\ ${ }^{1}$ China electric power research institute, Beijing 100085, China. \\ ${ }^{2}$ School of Metallurgical and Ecological Engineering, University of Science and Technology Beijing, \\ No. 30 College Road, Beijing 100083, China. \\ *E-mail: lijianling@ ustb.edu.cn
}

doi: $10.20964 / 2016.12 .91$

Received: 30 September 2016 / Accepted: 29 October 2016 / Published: 10 November 2016

\begin{abstract}
One-dimensional (1D) nanostructures provide shortened $\mathrm{Li}^{+}$diffusion pathways, structural stability and large interfacial area between the active material and electrolyte, which enhances the reversibility and cycling performance of spinel $\mathrm{Li}_{4} \mathrm{Ti}_{5} \mathrm{O}_{12}$ (LTO). Herein, we have successfully synthesized iodine (I) doping 1D LTO nanofibers by an electrospinning technique and studied the I doping effect on the lattice parameter, morphology and electrochemical properties of 1D LTO nanofibers. The 1D $\mathrm{Li}_{4} \mathrm{Ti}_{5} \mathrm{O}_{12-\mathrm{x}} \mathrm{I}_{\mathrm{x}}(\mathrm{x}=0.3)$ nanofibers have excellent rate capability, specific capacity and cycling stability because of the shortened diffusion length for $\mathrm{Li}^{+}$transport, which are mainly due to cubic lattice parameter of LTO increase with I doping. Also, Cyclic voltammetry (CV) and Electrochemical impedance spectroscopy (EIS) results confirmed that I doping can reduce the electrochemical polarization of LTO and increase the lithium ion diffusion coefficient, which can improve the electrochemical performance of LTO.
\end{abstract}

Keywords: $\mathrm{Li}_{4} \mathrm{Ti}_{5} \mathrm{O}_{12}$, Anode material, I-doping, Electrospinning, Lithium-ion battery

\section{$\underline{\text { FULL TEXT }}$}

(C) 2016 The Authors. Published by ESG (www.electrochemsci.org). This article is an open access article distributed under the terms and conditions of the Creative Commons Attribution license (http://creativecommons.org/licenses/by/4.0/). 